\title{
Perinatal testicular torsion-An emergency with grave consequences
}

\author{
Dietrich Doll ${ }^{1,2 \#}$, Josef Erkel ${ }^{3}$, Thomas Erhart ${ }^{1}$, Christian Hönemann $^{4}$ \\ ${ }^{1}$ Department of Surgery, Marienhospital Vechta, Academic Teaching Hospital of the Hannover University, Vechta, Germany; \\ "Corresponding Author: dolld@gmx.de, thomas.erhart@KK-OM.de \\ ${ }^{2}$ Department of Visceral, Thoracic and Vascular Surgery, Philipps-University of Marburg, Marburg, Germany \\ ${ }^{3}$ Department of Neonatology and Pediatric Care, Marienhospital Vechta, Academic Teaching Hospital of the Hannover University, \\ Vechta, Germany; Josef.Erkel@kk-om.de \\ ${ }^{4}$ Department of Anaesthesiology and Intensive Care, Marienhospital Vechta, Academic Teaching Hospital of the Hannover Univer- \\ sity, Vechta, Germany; Christian.Hoenemann@KK-OM.de
}

Received 23 January 2013; revised 26 February 2013; accepted 11 March 2013

\section{ABSTRACT}

Introduction: Perinatal testicular torsion is not a frequent, but a grave finding finding. As only immediate surgical retorsion may save the viability of the testicle, time is of essence. We report the case of a newborn where delayed diagnosis led to an unnecessary loss of one testicle. Presentation of Case: The newborn was presented one day after delivery with a swollen left blue scrotal pouch. The left testicle was little tender, higher in position and enlarged. Ultrasound revealed a globular, enlarged testicle left, showing hypodense necrotic areas within. Doppler sound could not detect any perfusion of the spermatic vessels. Scrotal fluid was present bilaterally. At operation, the testicle was considered unsalvageable, and left orchiectomy and right orchidopexy were performed. Discussion: In the newborn, it is more than convenient to perfom ultrasound of both testicles at the same time, which allows to compare texture and perfusion easily. Immediate surgical exploration should be performed at any time, even if in diagnostic doubt. The very most important step though is to professionally recognise and to react to this pediatric emergency, as time is of paramount essence. Conclusion: A case of a male newborn with unilateral perinatal testicular torsion is presented, where typical clinical signs and ultrasound features can be seen. Early exploration with orchiectomy of the necrotic testicle and orchidopexy of the healthy side may save the endocrine function and fertility.

\footnotetext{
"This article consists of original data neither presented nor published before. There is no conflict of interest. No financial, technical or writing support was accepted.
}

Keywords: Neonatal; Perinatal; Testicular Torsion; Testicular Necrosis; Orchidopexy; Acute Scrotal Swelling

\section{INTRODUCTION}

The testicles embryologically develop from the mesodermal bud proximal to the kidney, and usually find their way genetically determined into the scrotal pouch before birth or within the first months of life [1,2]. Spermatic cord torsion is a very rare event, and present in 1:7500 newborn [3]. A torsion occurring after, before or during birth, compromises the vascular supply up to full testicular necrosis with consequences tor fertility [3-5]. Immediately recognised, diagnosis can be easily proven noting the typical clinical appearance and characteristic ultrasound features [6]. As only immediate surgical retorsion may save the viability of the testicle, time is of essence. We report the case of a newborn where delayed diagnosis led to an unnecessary loss of one testicle.

\section{PRESENTATION OF CASE}

The newborn was presented to us one day after delivery in a small clinic. Transport time was less than one hour. At the time of birth his father had held his newborn son, inspected his private parts and noted a swollen scrotal pouch on the left side, which was slightly more bluish than the right side. Unfortunately, the midwife in charge did not react neither to his finding nor to her own inspection of the newborn. The following morning, after a routine examination by the attending doctor, transfer was arranged to our hospital, which comprises a large pediatric department, pediatric intensive care and surgical facilities.

On immediate examination, the affected left testicle was slightly tender, higher in position and enlarged with 
bluish color (Figure 1). The left testicle was of soft texture und not engorged.

Ultrasound revealed a globular, enlarged testicle on the left side, showing hypodense necrotic areas within (Figures 2 and 3). Doppler sound could not detect any perfusion of the spermatic vessels. Scrotal fluid was present bilaterally (Figure 4).

At operation, the spermatic cord looked viable but twisted (Figure 5), but left testicle was already decomposing ichorously, due to a full spermatic cord twist (Figures 6 and 7). The left testicle was considered unsalvageable, left orchiectomy and right orchidopexy were performed.

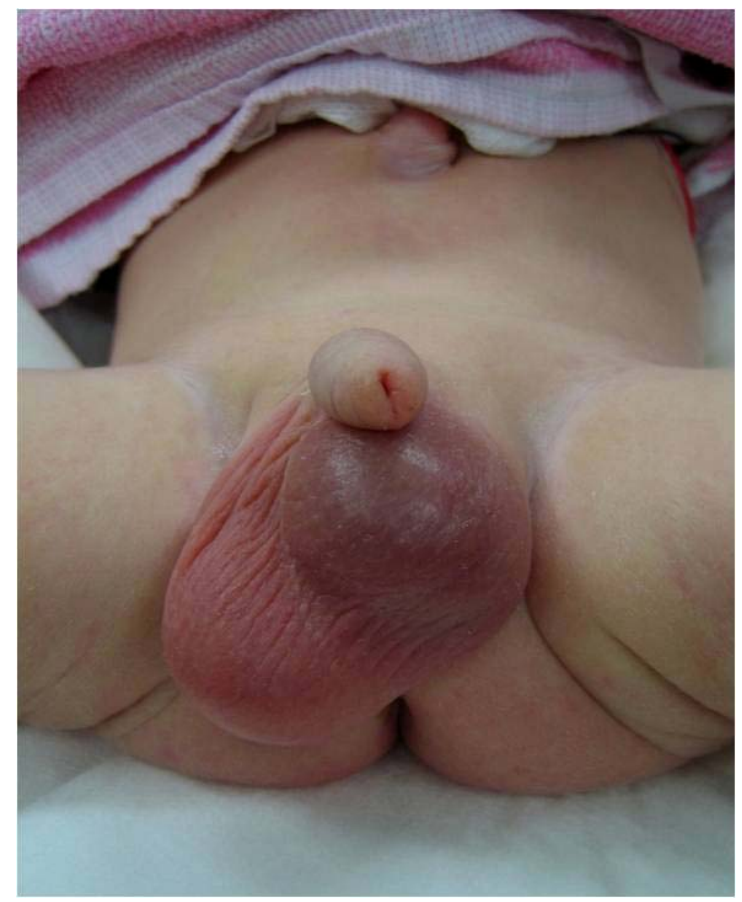

Figure 1. Higher standing, enlarged and bluish left scrotal area indicating hematoma or ischemic reaction present at time of birth (photo taken one day after birth).

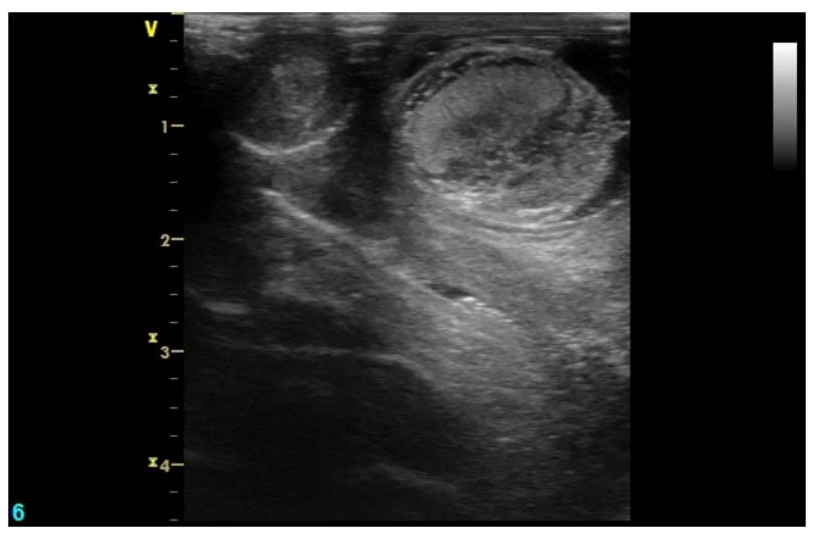

Figure 2. Enlarged left testicle compared to normal sized testicle at the right side.

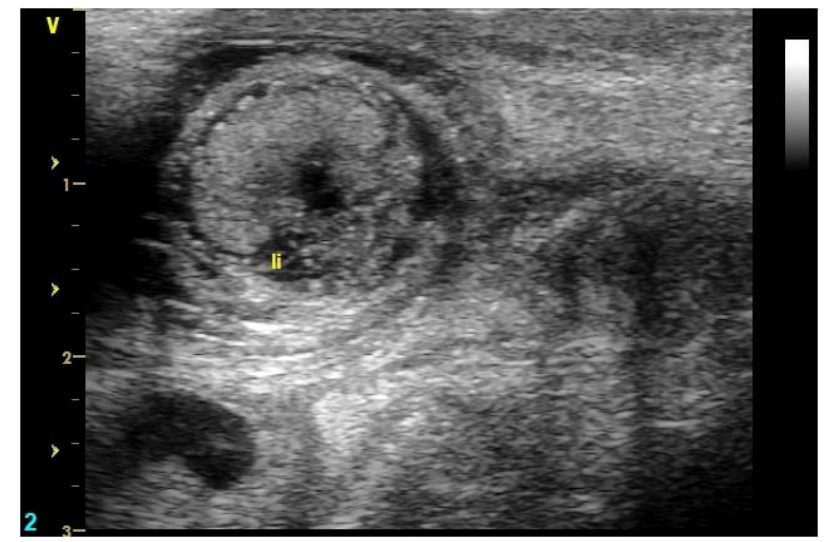

Figure 3. Left testicle with surrounding fluid and central necrosis.

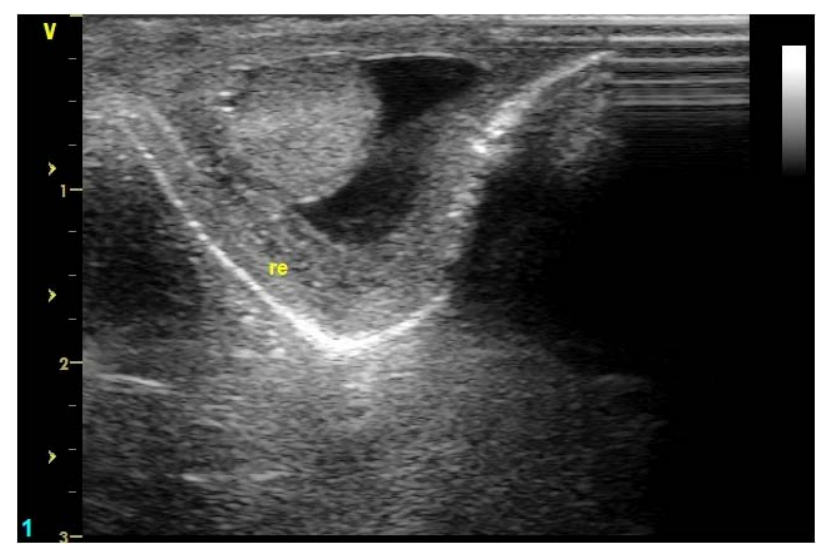

Figure 4. Normal texture of right testicle. Please note fluid around the healthy testicle.

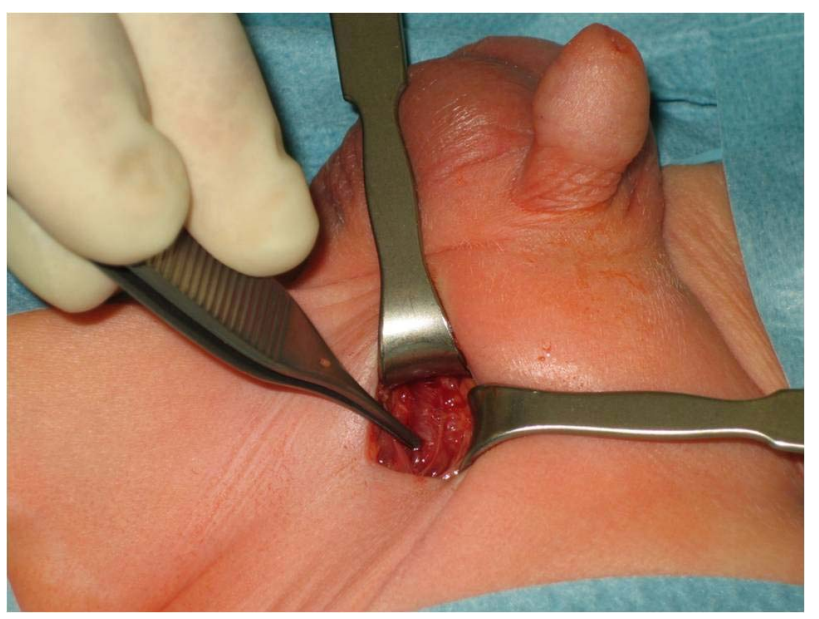

Figure 5. Obvious torsion of the spermatic cord, which itself is still viable.

\section{DISCUSSION}

A case of a first male newborn with unilateral neonatal testicular torsion is presented, where typical clinical signs and ultrasound features could be seen. In spite of typical 


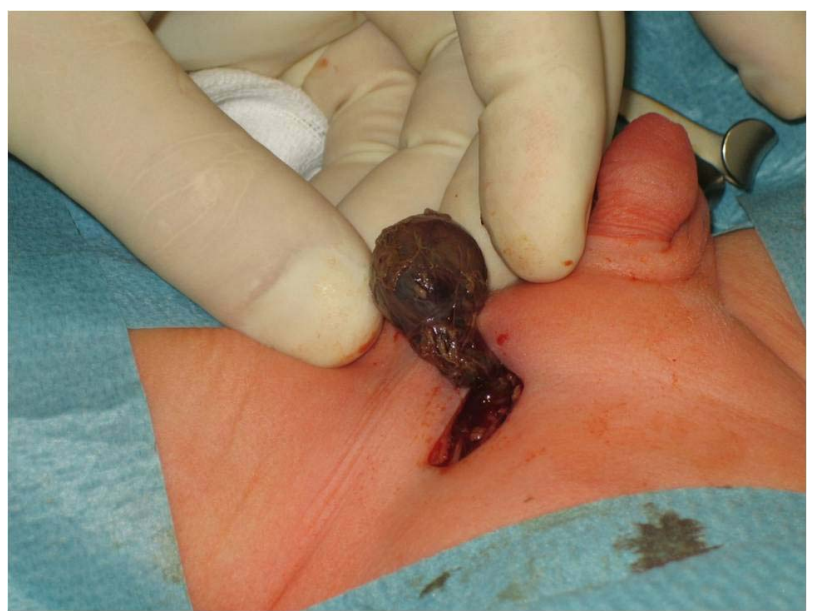

Figure 6. Necrotic left testicle.

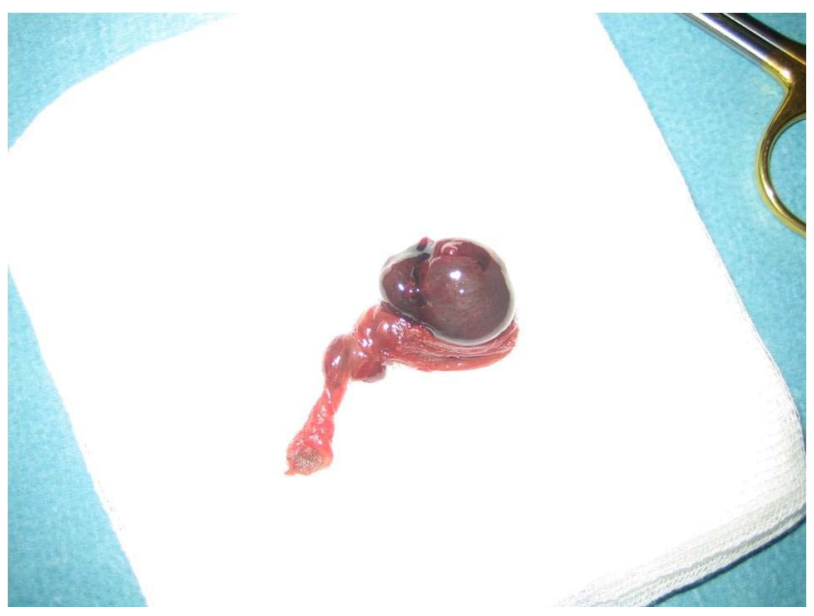

Figure 7. Resection specimen.

clinical features of testicular torsion at birth and the father's worried remarks, there was no prompt reaction taken by the responsible clinic.

Although there is no proof that the torsion was acquired during birth, which may be underlined by an already decomposing left testicle and a low level of pain, it may have been saved when still ischemic. If testicular torsion happens days before birth, the survival of the testicle is in real danger, depending on the degree of torsion and the time period of ischemia. Testicular torsion may happen fully or gradually, leaving testicles necrotic or ischemic. Diagnostic difficulties may arise if an undescended, intraabdominal testis torques before birth [7]. Ischemic organs may profit from conservative treatment, and regain full or near-full endocrine status $[8,9]$. This is especially important in the rare cases of bilateral torsion, where the danger of retarded development, slower body growth, missed puberty and infertility are common [1013].

Even if the attending personnel is in doubt if the higher standing, firm, enlarged testicle may be a hydatid cyst or a tumour, ultrasound in the skilled users' hand may reveal the typical features of one globular testicle without perfusion, containing peripheral and/or central necrotic hypodense areas [4,14-17]. Bilateral scrotal fluid is typically present, but is not proof of bilateral disease as shown above.

In the newborn, it is more than convenient to perform ultrasound of both testicles at the same time (Figure 2). This allows comparison of texture and perfusion easily. Immediate surgical exploration should be performed already at suspicion of testicular torsion $[6,18,19]$. An ischemic testicle may be rotated back into position and pexied, whereas an overt necrotic one has to be removed [20].

We wish to emphasize, as shown in this case report, that the very most important step is early recognition and reaction to this pediatric emergency by surgical exploration, as time is of paramount essence.

\section{CONCLUSION}

A case of a male newborn with unilateral neonatal testicular torsion is presented, where typical clinical signs and ultrasound features can be seen. Early exploration with orchiectomy of the necrotic testicle and orchidopexy of the healthy side may save the endocrine function and fertility.

\section{CONSENT}

Written informed consent was obtained from the parents of this newborn patient for publication of this case report and accompanying images. A copy of the written consent is available for review by the Editor-in-Chief of this journal on request.

\section{REFERENCES}

[1] Archambeault, D.R., Tomaszewski, J., Joseph, A., Hinton, B.T. and Yao, H.H. (2009) Epithelial-mesenchymal crosstalk in Wolffian duct and fetal testis cord development. Genesis, 47, 40-48. doi:10.1002/dvg.20453

[2] Vinci, G., Anjot, M.N., Trivin, C., Lottmann, H., Brauner, R. and McElreavey, K. (2004) An analysis of the genetic factors involved in testicular descent in a cohort of 14 male patients with anorchia. The Journal of Clinical Endocrinology \& Metabolism, 89, 6282-6285. doi:10.1210/jc.2004-0891

[3] Ahmed, S.J., Kaplan, G.W. and DeCambre, M.E. (2008) Perinatal testicular torsion: Preoperative radiological findings and the argument for urgent surgical exploration. Journal of Pediatric Surgery, 43, 1563-1565. doi:10.1016/j.jpedsurg.2008.03.056

[4] Baptist, E.C. and Amin, P.V. (1996) Perinatal testicular torsion and the hard testicle. Journal of Perinatology, 16, 67-68. 
[5] Gorbonos, A. and Cheng, E.Y. (2007) Perinatal testicular torsion in siblings. Journal of Pediatric Urology, 3, 514515. doi:10.1016/j.jpurol.2007.04.009

[6] Orazi, C., Schingo, P., Ferro, F., Vacca, P., Spagnoli, A. and Fariello, G. (1997) Does B-mode ultrasound still have a role in the diagnosis of spermatic cord torsion? Findings in a pediatric series. Radiologia Medica, 94, 646-651.

[7] Campbell, J.R. and Schneider, C.P. (1976) Intrauterine torsion of an intra-abdominal testis. Pediatrics, 57, 262264.

[8] Ching, C.B. and Jones, J.S. (2011) Incomplete prenatal torsion of the testicle-A successful salvage. Urology, 78, 1182-1184. doi:10.1016/j.urology.2011.02.021

[9] Roth, C.C., Mingin, G.C. and Ortenberg, J. (2011) Salvage of bilateral asynchronous perinatal testicular torsion. Journal of Urology, 185, 2464-2468. doi:10.1016/j.juro.2011.01.013

[10] Arena, F., Nicotina, P.A., Scalfari, G., Visalli, C., Arena, S., Zuccarello, B. and Romeo, G. (2005) A case of bilateral prenatal testicular torsion: Ultrasonographic features, histopathological findings and management. Journal of Pediatric Urology, 1, 369-372. doi:10.1016/j.jpurol.2005.03.001

[11] Bagci, S., Bachour, H., Woelfle, J.F., Mueller, A., Bartmann, P. and Franz, A.R. (2010) Bilateral perinatal testicular torsion in an infant: A rare neonatal emergency. Pediatrics International, 52, e227-e228. doi:10.1111/j.1442-200X.2010.03139.x

[12] Olguner, M., Akgur, F.M., Aktug, T. and Derebek, E. (2000) Bilateral asynchronous perinatal testicular torsion: A case report. Journal of Pediatric Surgery, 35, 13481349 doi:10.1053/jpsu.2000.9330

[13] Zampieri, N., Cecchetto, M., Ottolenghi, A. and Camoglio, F.S. (2009) Bilateral testicular torsion: An extremely tragic rare condition. Minerva Pediatrica, 61, 455-457.
[14] Calonge, W.M., Heitor, F., Castro, L.P., Meruje, M., Coutinho, S.P., Cunha, C. and de Ochoa, C.A. (2004) Neonatal paratesticular neuroblastoma misdiagnosed as in utero torsion of testis. Journal of Pediatric Hematology/Oncology, 26, 693-695. doi:10.1097/01.mph.0000141896.97372.ce

[15] Nitzsche, K., Kamin, G., Dittert, D.D., Bier, A. and Distler, W. (2009) Fetal juvenile granulosa cell tumor with hermaphroditism verus prenatal diagnosis, management and outcome. Ultraschall in Der Medizin, 30, 404-407. doi:10.1055/s-2007-963556

[16] Cesca, E., Midrio, P., Tregnaghi, A., Alaggio, R., Bitetti, S. and Gamba, P. (2009) Meconium periorchitis: A rare cause of fetal scrotal cyst-MRI and pathologic appearance. Fetal Diagnosis and Therapy, 26, 38-40. doi:10.1159/000236358

[17] Brown, S.M., Casillas, V.J., Montalvo, B.M. and AlboresSaavedra, J. (1990) Intrauterine spermatic cord torsion in the newborn: Sonographic and pathologic correlation. Radiology, 177, 755-757.

[18] Burks, D.D., Markey, B.J., Burkhard, T.K., Balsara, Z.N., Haluszka, M.M. and Canning, D.A. (1990) Suspected testicular torsion and ischemia: Evaluation with color Doppler sonography. Radiology, 175, 815-821.

[19] O’Hara, S.M., Frush, D.P., Babcock, D.S., Lewis, A.G., Barr, L.L., Bukowski, T.P., Kline-Fath, B.M. and Sheldon, C.A. (1996) Doppler contrast sonography for detecting reduced perfusion in experimental ischemia of prepubertal rabbit testes. Academic Radiology, 3, 319-324. doi:10.1016/S1076-6332(96)80249-2

[20] Van, G.E., Philippe-Chomette, P., Gall, O., Oro, H., Larroquet, M. and Audry, G. (2000) Spermatic cord torsion in the newborn: Role of surgical exploration. Archives of Pediatrics, 7, 1072-1076. doi:10.1016/S0929-693X(00)00315-8 